\title{
LA-UR-12-21798
}

Approved for public release; distribution is unlimited.

Title:

\section{PATRIOT SCRIPT User's Guide}

\author{
Author(s): $\quad$ Cuellar, Leticia \\ Cleland, Timothy J. \\ Kubicek, Deborah A. \\ Mathis, Mark M. \\ Stroud, Phillip D.
}

Intended for:

Documentation for Sponsor

\section{- LosAlamos \\ EST. 1943}

Disclaimer:

Los Alamos National Laboratory, an affirmative action/equal opportunity employer,is operated by the Los Alamos National

Security, LLC for the National NuclearSecurity Administration of the U.S. Department of Energy under contract DE-AC52-06NA25396.

By approving this article, the publisher recognizes that the U.S. Government retains nonexclusive, royalty-free license to

publish or reproduce the published form of this contribution, or to allow others to do so, for U.S. Government purposes.

Los Alamos National Laboratory requests that the publisher identify this article as work performed under the auspices of the

U.S. Departmentof Energy. Los Alamos National Laboratory strongly supports academic freedom and a researcher's right to publish; as an institution, however, the Laboratory does not endorse the viewpoint of a publication or guarantee its technical correctness. 


\title{
2012
}

\section{PATRIOT SCRIPT}

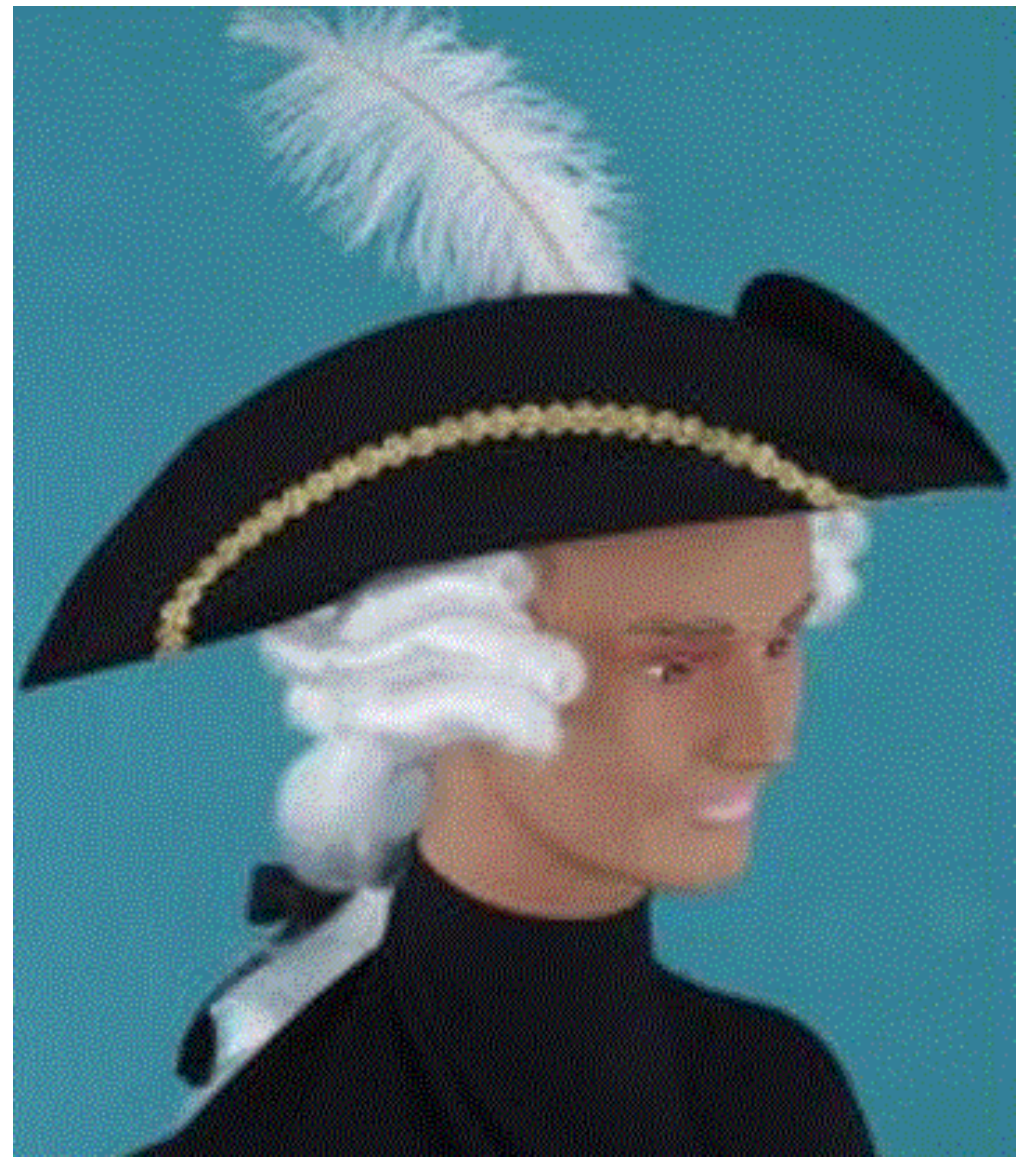

Users' Guide

\author{
L. Cuéllar, T. Cleland, \\ D. Kubicek, M. Mathis, \\ P. Stroud
}

Los Alamos National Laboratory

$5 / 31 / 2012$ 


\section{PATRIOT Script}

\section{Introduction}

PATRIOT Script is an application that executes Patriot batch runs. This document provides a description of this application and how to run it. The basic user access tool PATRIOT Client allows a user to generate several most reliable paths in one run: one can specify a list of sources (origins) and targets, and PATRIOT finds for a given architecture option and one choice of device all the most reliable paths between all these sources and targets. The main objective of PATRIOT Script is to provide a tool for making automatic PATRIOT runs not only for a prespecified set of sources and targets, but also for a pre-specified set of devices and various architecture options.

Running PATRIOT Script requires two basic steps that will be explained in more detail next:

1. Pre-preparation of an excel spreadsheet with the information about the desired runs.

2. Opening the PATRIOT Script application, reading in the excel-spreadsheet and running the desired scenarios.

Sections 1 and 2 explain each of these steps, and section 3 describes the output of the PATRIOT Script. For a detail description of the models and data behind PATRIOT and a detailed explanation of all the architecture options see [1]. For instructions of how to run PATRIOT Client see [2].

\section{Preparing the Excel Spreadsheet with the Desired Scenarios}

We first input the desired scenarios to be run in an excel-spreadsheet that can be imported by the Patriot script. Figure 1 shows the format the PATRIOT Script requires. Most of the lines are self explanatory, but we explain all of them next. Note that the PATRIOT Script does expect some blank lines, like lines 1,4 , and 7.

\section{Line 1. Blank}

Line 2. Sources: First cell expects a query for the sources. Typically a search string like "swamisource terminal" will find all the swami sources terminals, where terminal refers to one of the three terminal nodes in which we expand a normal network node, the other two terminal nodes being Arrival and Departure. If only a subset of all the "swamisources terminals" is desired, these can be specified one by one in row 2 starting in cell 2 . 
Line 3. Targets: Similarly as for the selection of the sources, PATRIOT Script will expect in the first cell a query for the targets. A simple query like "swamitarget terminals" provides all the swami target terminals, and a subset can be specified starting in cell 2 .

\section{Line 4. Blank}

Figure 1 Specification of Scenarios in an Excel-spreadsheet

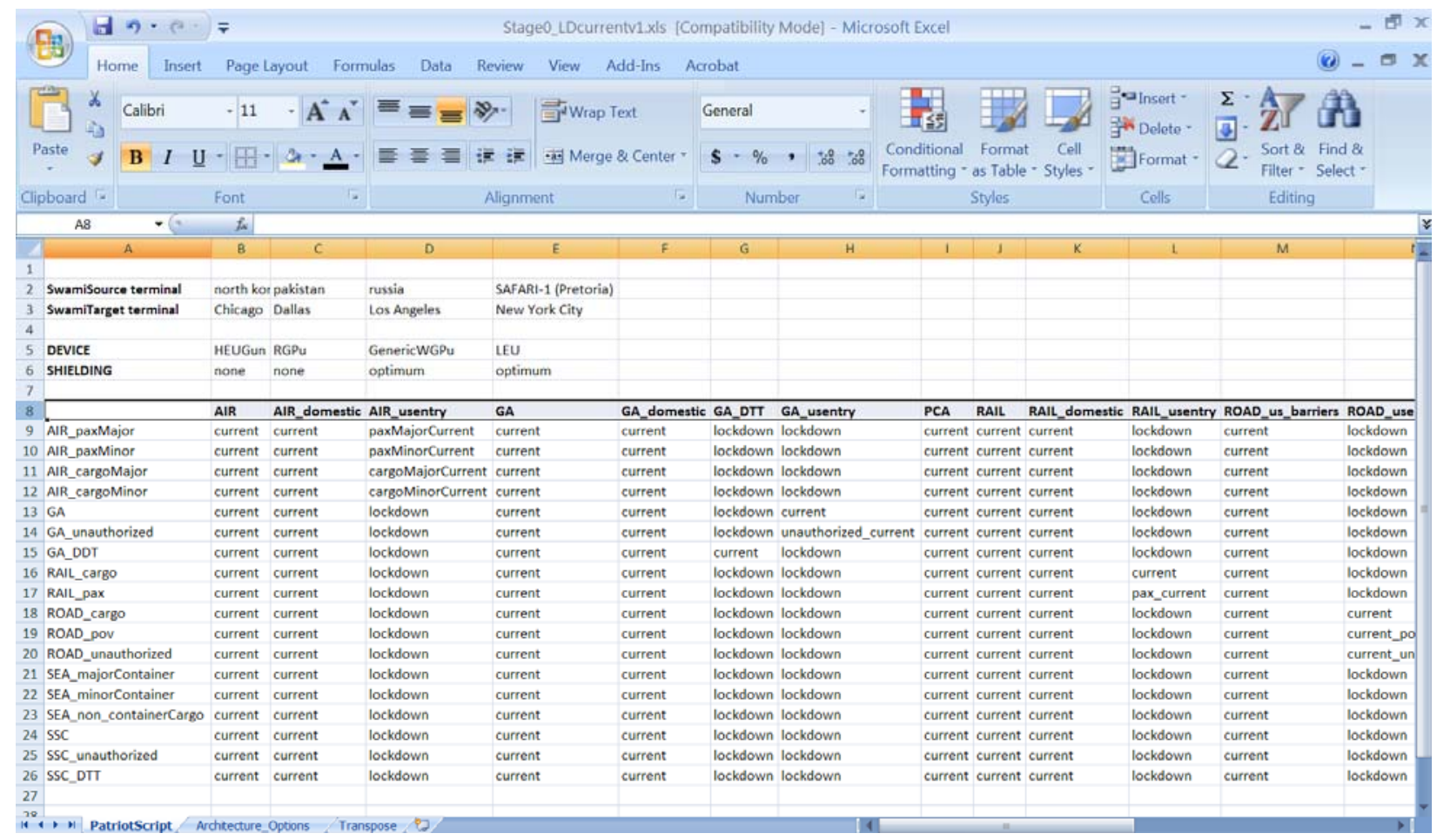

Line 5 and 6. Devices: The 16 new device weight and brightness categories are selected by specifying a combination of one of the previous 8 devices with the appropriate type of shielding. Table 1 provides the appropriate mapping. Thus we specify the old device name in Line 5 and the desired shielding in Line 6.

Table 1 Mapping of the new PATRIOT devices to the old ones.

\begin{tabular}{|l|c|c|c|c|c|c|c|c|}
\hline $\begin{array}{l}\text { New } \\
\text { Device }\end{array}$ & $\begin{array}{c}\text { pseudobare } \\
\text { very-light }\end{array}$ & $\begin{array}{c}\text { very bright } \\
\text { very-light }\end{array}$ & $\begin{array}{c}\text { very bright } \\
\text { medium }\end{array}$ & $\begin{array}{c}\text { bright } \\
\text { very-light }\end{array}$ & $\begin{array}{c}\text { bright } \\
\text { medium }\end{array}$ & $\begin{array}{c}\text { white } \\
\text { very light }\end{array}$ & $\begin{array}{c}\text { white } \\
\text { light }\end{array}$ & $\begin{array}{c}\text { white } \\
\text { heavy }\end{array}$ \\
\hline $\begin{array}{l}\text { OLD } \\
\text { Device }\end{array}$ & $\begin{array}{c}\text { HEUImpl } \\
\text { Shield* }\end{array}$ & $\begin{array}{c}\text { RGPu } \\
\text { None* }\end{array}$ & $\begin{array}{c}\text { LEU } \\
\text { none }\end{array}$ & $\begin{array}{c}\text { WGPu } \\
\text { none }\end{array}$ & $\begin{array}{c}\text { GenRGPu } \\
\text { shield }\end{array}$ & $\begin{array}{c}\text { HEU } \\
\text { none }\end{array}$ & $\begin{array}{c}\text { LEU } \\
\text { shield }\end{array}$ & $\begin{array}{c}\text { GenRGPu } \\
\text { none }\end{array}$ \\
\hline \\
\hline $\begin{array}{l}\text { New } \\
\text { Device }\end{array}$ & $\begin{array}{c}\text { light gray } \\
\text { medium }\end{array}$ & $\begin{array}{c}\text { light gray } \\
\text { heavy }\end{array}$ & $\begin{array}{c}\text { gray } \\
\text { light }\end{array}$ & $\begin{array}{c}\text { gray } \\
\text { heavy }\end{array}$ & $\begin{array}{c}\text { dark gray } \\
\text { very light }\end{array}$ & $\begin{array}{c}\text { dark gray } \\
\text { light }\end{array}$ & $\begin{array}{c}\text { dark gray } \\
\text { medium }\end{array}$ & $\begin{array}{c}\text { dark gray } \\
\text { heavy }\end{array}$ \\
\hline $\begin{array}{l}\text { OLD } \\
\text { Device }\end{array}$ & $\begin{array}{c}\text { GenWGPu } \\
\text { shield }\end{array}$ & $\begin{array}{c}\text { HEUImpl } \\
\text { none }\end{array}$ & $\begin{array}{c}\text { HEUGun } \\
\text { shield }\end{array}$ & $\begin{array}{c}\text { GenWGPu } \\
\text { none }\end{array}$ & $\begin{array}{c}\text { HEU } \\
\text { shield }\end{array}$ & $\begin{array}{c}\text { WGPu } \\
\text { shield }\end{array}$ & $\begin{array}{c}\text { RGPu } \\
\text { shield }\end{array}$ & $\begin{array}{c}\text { HEUGun } \\
\text { none }\end{array}$ \\
\hline
\end{tabular}

shield: optimum shielding

none: no shielding 


\section{Line 7. Blank}

Line 8. Architecture Options: columns B through $X$ contain the names of the 23 Patriot architecture options shown in Table 2.

\section{Table 2 PATRIOT Architecture Options}

\begin{tabular}{|l|l|}
\hline \multicolumn{2}{|c|}{ PATRIOT Architecture Options } \\
\hline 1. AIR & 12. ROAD_us_barriers \\
2. AIR_domestic & 13. ROAD_usentry \\
3. AIR_usentry & 14. ROAD_us_PRD \\
4. GA & 15. ROAD_us_rings \\
5. GA_domestic & 16. SCP \\
6. GA_DTT & 17. SEA \\
7. GA_usentry & 18. SEA_usentry \\
8. PCA & 19. SLD \\
9. RAIL & 20. SLD_mobile \\
10. RAIL_domestic & 21. SSC \\
11. RAIL_usentry & 22. SSC_DTT \\
& 23. SSC_usentry \\
\hline
\end{tabular}

Line 9-Line $\mathbf{n}$. Architecture Levels: Each of these lines serve to indicate the desired combination of architecture levels for each of the 23 Patriot Architecture Options. Column A serves to name the architecture levels combinations. Each scenario name needs to be unique.

For example, in the example shown in Figure 1, line 9 displays the "AirPAxMajor" run, where all U.S. modes of entry are set to lockdown, except for AIR_usentry (column D) that was set to pax_MajorCurrent, and all other options are set to current. For this specific choice of architecture options, PATRIOT Script will find the most reliable paths between all 4 sources and 4 targets and for all 4 devices producing a total of $64(4 \times 4 \times 4)$ most reliable paths.

Note: PATRIOT Script does expect the correct spelling for each of the architecture levels. Table 3 contains all the architecture options with all of their respective architecture levels. A template will be provided with the distribution of this code called Arch_options_template_May2012.xls. The second tab (sheet) of this template contains all the architecture levels to make it easier to copy and paste into the first tab (sheet). 
Table 3 Patriot Architecture Options and their Levels

\begin{tabular}{|c|c|c|c|c|c|c|c|}
\hline \multirow{2}{*}{$\begin{array}{l}\begin{array}{c}\text { ARCHITECTURE } \\
\text { OPTIONS }\end{array} \\
\text { AIR } \\
\end{array}$} & \multicolumn{7}{|c|}{ ARCHITECTURE LEVLES } \\
\hline & curremt & lockdown_workdwilde & & & & & \\
\hline AIR_domestic & curremt & plus 50 & top 26 & top50 & top75 & top 100 & lockdown \\
\hline \multirow[t]{2}{*}{ AIR_usentry } & curremt & parCustomsBoost & paxMajorCurrent & paxMajorBoost & paxlulnorCurrent & paxMlinorBoost & cargoMajorCurremt \\
\hline & & cargoMajorBoost & cargoMInorCurrent & cargo MInorBoost & majorEnhanced & minorEnhanced & lockdown \\
\hline GA & current & lockdown_worldwilde & & & & & \\
\hline GA_domestic & curremt & boost & enhanced & lockdown & & & \\
\hline GA_DTT & current & plus50 & enhanced & lockdown & & & \\
\hline GA_usentry & curremt & boost & unauthorlzed_current & unauthorlzed_boost & enhanced & lockdown & \\
\hline PCA & current & enhanced & & & & & \\
\hline RAIL & curremt & lockdown_workdwhle & & & & & \\
\hline RAIL_domestic & curremt & plus50 & enhanced & lockdown & & & \\
\hline RAIL_usentry & current & plus50 & pax_current & pax_boost & enhanced & lockdowm & \\
\hline ROAD_us_barrlers & current & plus50desert & plus50mountaln & plus50rtser & lockdown & & \\
\hline \multirow[t]{2}{*}{ ROAD_usentry } & current & plus50 & current_pov & boost_pow & current_unaut horlzed & boost_unauthorlzed & bypass 50 \\
\hline & & & bypass 90 & enhanced & lockdown & & \\
\hline ROAD_us_PRD & current & plus50backpack & plus50rild & PRD_StatesInventory & plus50 & heavyMDDz0000 & heavyMDD4000 \\
\hline \multirow[t]{2}{*}{ ROAD_us_rings } & curremt & plus50_all_surge & plus100_all_surge & plus200_all_surge & plus400_all_surge & plus50_NYNJ_surge & plus50_rild_equip \\
\hline & & plus50_rpm_equlp & plus50backpack & enhanced & lockdown & & \\
\hline SCP & curremt & enhanced & lockdown & & & & \\
\hline SEA & curremt & lockdown_workdwhle & & & & & \\
\hline \multirow[t]{2}{*}{ SEA_usentry } & curremt & plus 50 & major_contalner_current & major_contalner_boost & major_comtalner_enhanced & minor_comtalner_current & mlnor_comtalner_boost \\
\hline & & \multicolumn{2}{|c|}{ mlnor_contalner_enhanced } & enhanced & lockdown & & \\
\hline SLD & curremt & plus 50 & customs_unlon & all_roads_off & & & \\
\hline SLD_moblle & curremt & 5ld_4k & skd_20k & & & & \\
\hline ssc & curremt & lockdown_workdwhle & & & & & \\
\hline SSC_DTT & current & boost & enhanced & lockdown & & & \\
\hline SSC_usentry & curremt & group1 & allgroups & plus50backpack & plus50hpt & InerCargoCurrent & talnerCargoBoost \\
\hline & & unauthorlzedCu rrent & unauthorlzed Boost & enhanced & lockdown & & \\
\hline
\end{tabular}

\section{Running the Patriot Script Application}

To run the PATRIOT Script application, double click on the PATRIOT Script icon located in C:LANL\PEM1.2\Applications\patriotscrit.exe or the application can be started be doubleclicking on the PATRIOT Script icon on the desktop. If a new window appears (as the image shown on the right hand side of Figure 2), click on the "Run" tab. You can also uncheck the box indicating "Always ask before opening this file" to not have this window pop-up again.

Figure 2 Running the Patriot Script Application
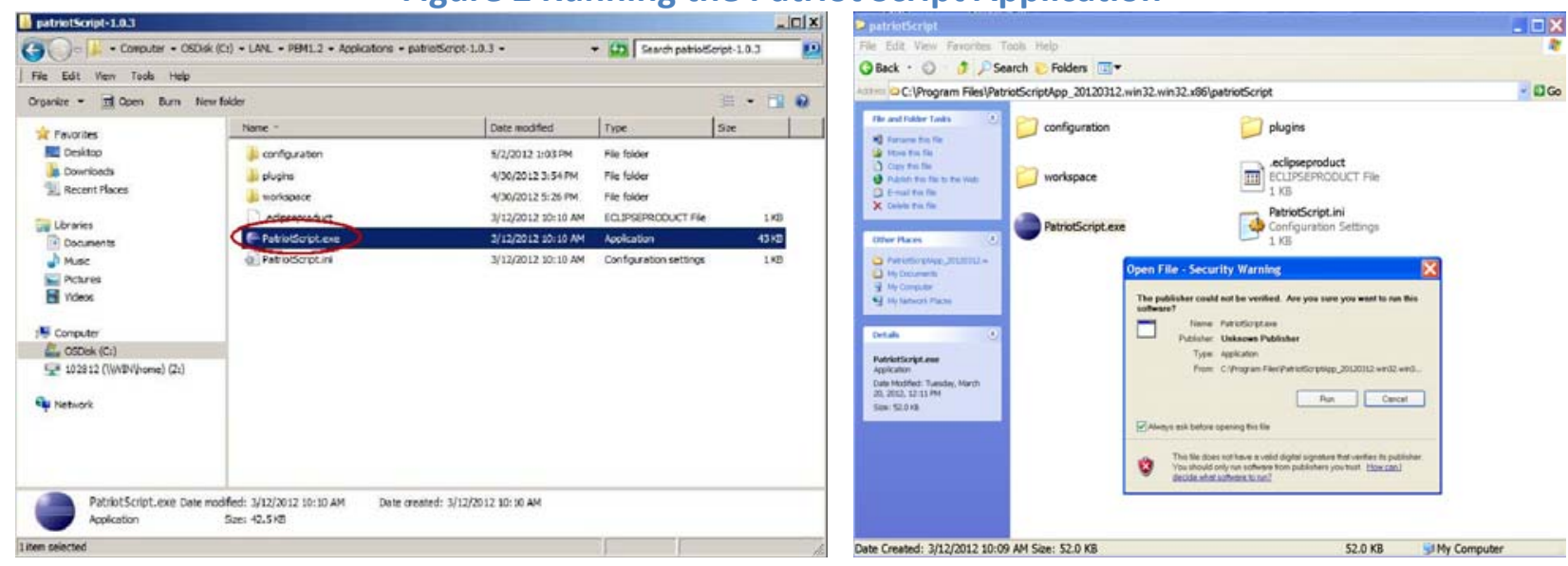
Then the Patriot Script Application will open as shown in Figure 3.

Figure 3 Patriot Script Application
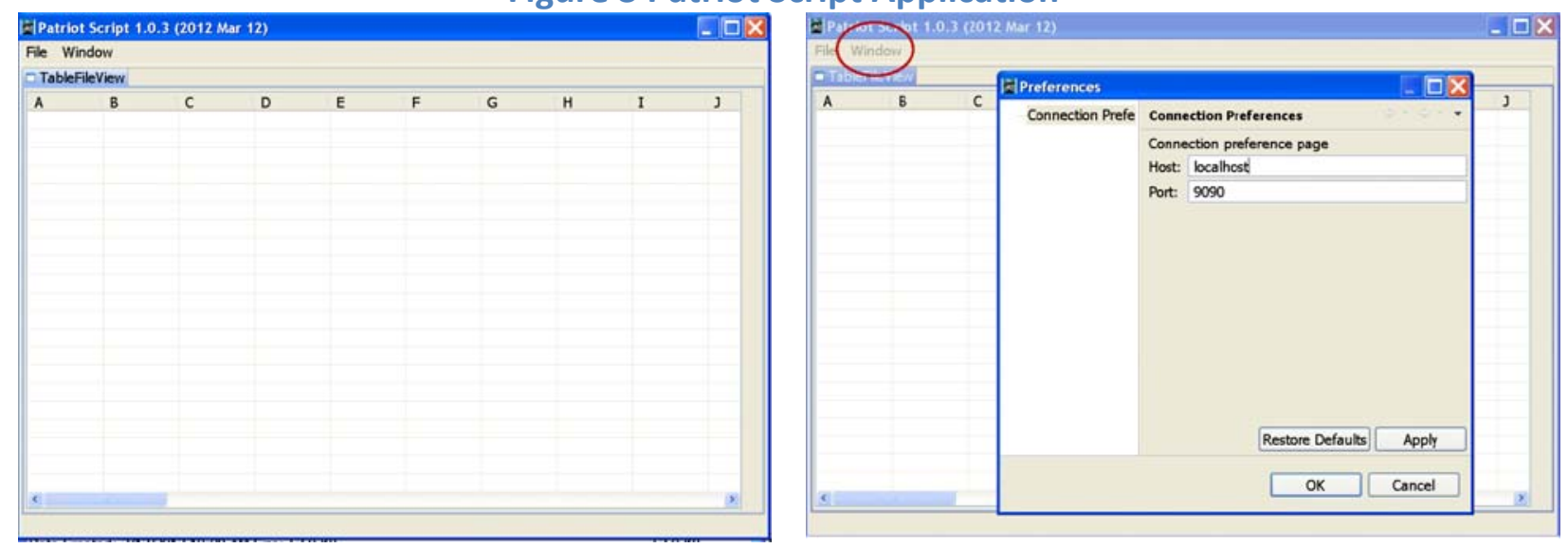

To choose the server and port, go to the Window tab in the upper left corner, select Preferences, and write localhost and 9090 for the host and port respectively. If the PATRIOT server is running on a Virtual Machine (VM), then one needs to specify the VM's IP address instead of localhost.

Next, to read in the Excel Spreadsheet for the desired scenarios to be run, go to the FILE tab in the upper left corner, click on Open and select the file with the spreadsheet prepared as described in the previous section (see Figure 4).

Figure 4 Rean in the pre-prepared excel spreadsheet

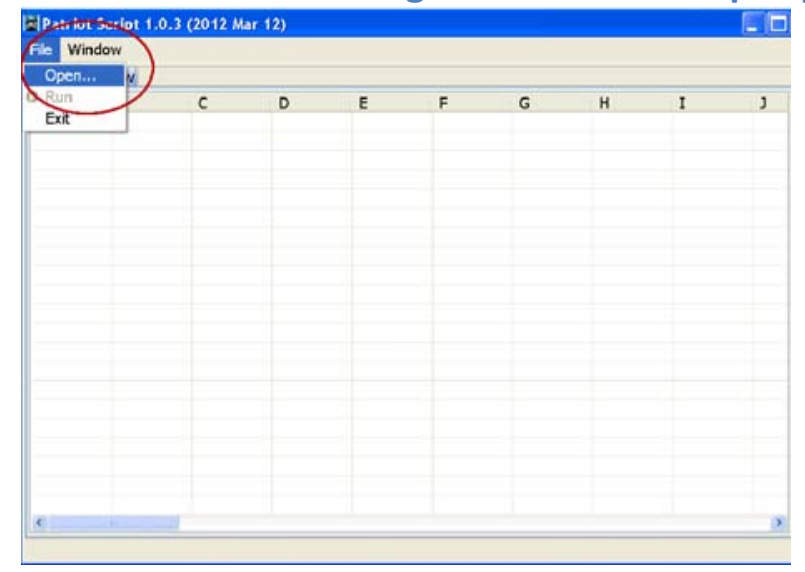

\begin{tabular}{|c|c|c|c|c|c|c|}
\hline El Patriot Script 1.0.3 & D12 Mar 12) & & & & & $-\square$ \\
\hline File Window & & & & & & \\
\hline TablefileView & & & & & & \\
\hline A & B & c & D & E & $F$ & G \\
\hline SwamiSource terminal & north korea & pakistan & russia & SAFARI-1 (Pretoria) & & \\
\hline SwamiTarget terminal & Chicago & Dallas & Los Angeles & New York City & & \\
\hline DEVICE & HEUGun & RGPU & GenericWGPu & LEU & & \\
\hline SHIELDING & none & none & optimum & optimum & & \\
\hline AIR paxMajor & $\begin{array}{l}\text { AIR } \\
\text { current }\end{array}$ & $\begin{array}{l}\text { AIR_do... } \\
\text { current }\end{array}$ & $\begin{array}{l}\text { AIR usentry } \\
\text { paxMajorCurrent }\end{array}$ & $\begin{array}{l}\text { GA } \\
\text { current }\end{array}$ & $\begin{array}{l}\text { GA_do... } \\
\text { current }\end{array}$ & $\begin{array}{l}\text { GA D } \\
\text { lockde }\end{array}$ \\
\hline AIR paxMinor & current & current & paxMinorCurrent & current & current & lockdt \\
\hline AIR_cargomajor & current & current & cargoMajorCurrent & current & current & lockdk \\
\hline AIR cargominor & current & current & cargoMinorCurrent & current & current & lockdt \\
\hline GA & current & current & lockdown & current & current & lockdk \\
\hline GA_unauthorized & current & current & lockdown & current & current & lockdk \\
\hline GADDT & current & current & lockdown & current & current & curres \\
\hline RAIL_cargo & current & current & lockdown & current & current & lockde \\
\hline RAIL_pax & current & current & lockdown & current & current & lockdk \\
\hline ROAD_cargo & current & current & lockdown & current & current & lockdk \\
\hline ROAD_pov & current & current & lockdown & current & current & lockdk \\
\hline ROAD_unauthorized & current & current & lockdown & current & current & lockde \\
\hline SEA_majorContainer & current & current & lockdown & current & current & lockde \\
\hline
\end{tabular}


Finally, to run the application, click again the FILE tab in the upper left corner, and select Run (see Figure 5). The Application will ask for a location where to save the results. Specify the directory where all the results will be saved.

\section{Figure 5 Running the Script}

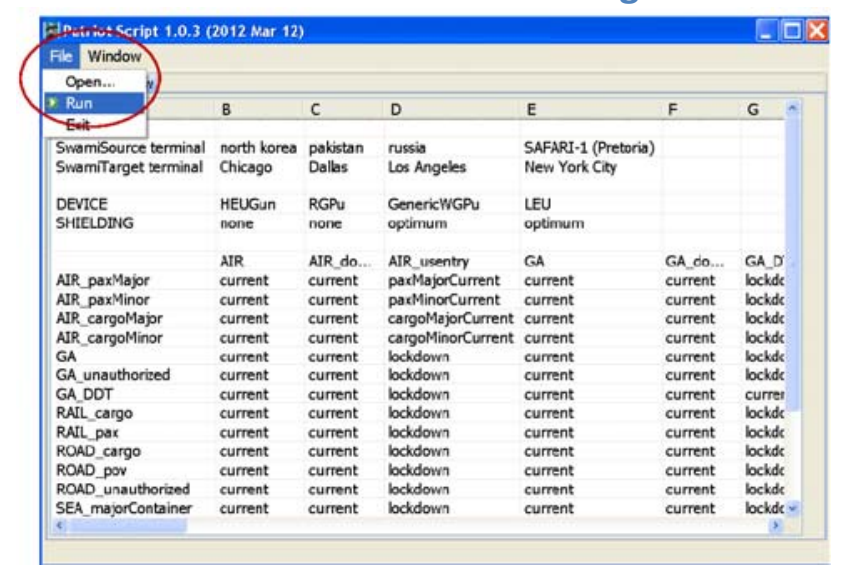

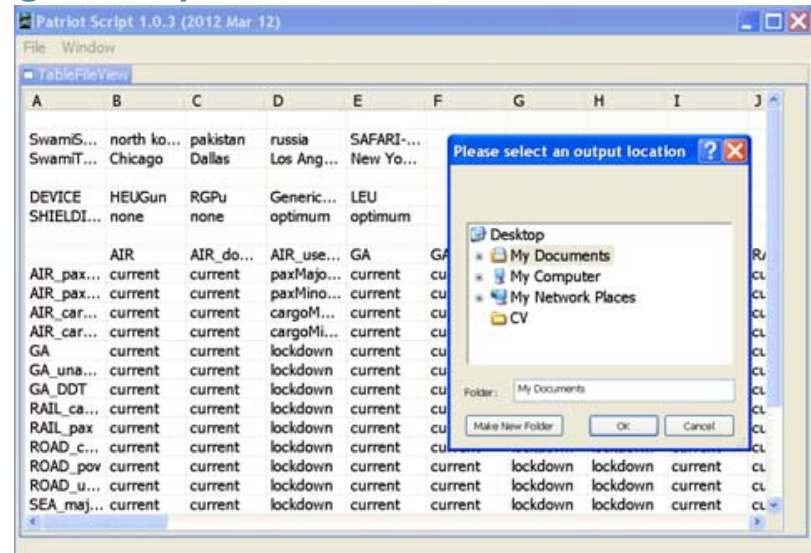

\section{Patriot Script Output}

In the directory chosen to save the results, the PATRIOT Script application will write a csv file with the output for all individual PATRIOT runs. This file can easily be read with Excel.

The PATRIOT Script application will also automatically create a new folder with all the KML files containing the most reliable paths. Each file will contain all the paths between all sources and targets for a given device and a given combination of architecture options.

\section{REFERENCES}

[1] Cuéllar, L., D. Kubicek, M. Mathis, F. Roach, J. Smith, P. Stroud 2012). Probabilistic Effectiveness Methodology, Data Documentation V1.2, LA-CP 12-00659, Los Alamos National Laboratory, Los Alamos, NM.

[2] Mathis, M. and D. Kubicek (2011). PATRIOT Quick Start Guide, Los Alamos National Laboratory, Los Alamos, NM. 